\title{
Preservação digital na gestão de processos administrativos de uma instituição de ensino superior: o caso dos PEAPDs da PROGEP da UFSM
}

\author{
Crislei Daiana Oliveira Siqueira Schuch \\ Mestre; Universidade Federal de Santa Maria, Santa Maria, RS, Brasil; \\ crislei.schuch@gmail.com \\ Denise de Souza Saad \\ Doutora; Universidade Federal de Santa Maria, Santa Maria, RS, Brasil; \\ dssaad1@gmail.com

\section{Daniel Flores} \\ Doutor; Universidade Federal de Santa Maria, Santa Maria, RS, Brasil; \\ dfloresbr@gmail.com
}

\begin{abstract}
Resumo: Sabe-se que a evolução das tecnologias da informação foi acompanhada pelo aumento de sua importância para as organizações. Assim, este estudo buscou propor um modelo de gestão de preservação digital, em longo prazo, dos processos administrativos de exercícios anteriores de Progressão Docente da Pró-Reitoria de Gestão de Pessoas da Universidade Federal de Santa Maria, para viabilizar que esses processos possam, no futuro, ser criados em formato digital e preservados em repositórios arquivísticos digitais confiáveis. Para tanto, foi realizada uma pesquisa de natureza aplicada, com abordagem quali-quantitativa. No tocante aos objetivos, pesquisa descritiva. Os resultados demonstraram que o objetivo foi cumprido, na medida em que foi desenvolvido o Modelo de Gestão de Preservação Digital, adaptado para manter a cadeia de custódia e a autenticidade dos documentos dos Processos de Exercícios Anteriores de Progressão Docente. No futuro, os documentos poderão ser produzidos nato digitais no Sistema de Informações para o Ensino.
\end{abstract}

Palavras-chave: Preservação digital. Documento arquivístico digital. Autenticidade. Tecnologia de Informação e Comunicação. Universidade Federal de Santa Maria. 


\section{Introdução}

Segundo Pinochet (2014), no pós-modernismo (fenômeno típico da sociedade pós-industrial que é baseada no uso da informação), predomina a troca de informações de forma instantânea e quase imediata. Nesse sentido, conforme Grácio (2011), pesquisas têm demonstrado uma preocupação cada vez maior por parte das instituições com o problema da preservação digital, e também a demonstração de que grande parte destas ainda carece de maior sistematização das atividades relacionadas ao tema e de uma cultura de preservação digital.

Conforme relata Keiser (2017, tradução nossa), uma bibliotecária da Universidade da Califórnia sublinha que a preservação é política, nunca neutra. Ela descreveu como as práticas de preservação digital precisam ser descolonizadas, recomendando que abordemos as desigualdades perpetuadas em nossas práticas de arquivamento e que podemos fazê-lo usando a justiça contributiva, na qual todos têm a responsabilidade e a oportunidade de contribuir com trabalho e participar na tomada de decisão.

O tema política de preservação digital tem sido bastante discutido, impulsionado pelas inovações das Tecnologias da Informação e Comunicação (TICs), da Lei $\mathrm{n}^{\circ} 12.527$ (BRASIL, 2011), que estabelece o direito de acesso dos cidadãos às informações públicas; e por projetos como o InterPARES (International Research on Permanent Authentic Records in Electronic Systems) - Pesquisa Internacional sobre Documentos Arquivísticos Autênticos Permanentes em Sistemas Eletrônicos.

Ao passo que as demandas sociais mudam rapidamente, surgem novas necessidades, as quais forçam os serviços públicos a se prepararem para atendêlas de forma ágil, uma vez que, segundo Saad (2003, p. 283), “[...] o mundo da informação digital tem à sua disposição um conjunto de ferramentas especificamente desenvolvidas para se adequarem às necessidades de busca, armazenamento e filtragem das informações".

Nesse contexto, uma das tecnologias utilizadas é o Gerenciamento Eletrônico de Documentos (GED), o qual trabalha com documentos em formatos tradicionais, digitalizados ou criados em meio digital, gerenciando-os 
durante todo o seu ciclo vital e implementando soluções para armazenamento eficiente e rápido acesso às informações (SANTOS; CHARÃO; FLORES, 2003). No entanto, como um GED, em sua essência, não atende a todos os requisitos arquivísticos, o recurso utilizado para complementá-lo é o Sistema Informatizado de Gestão Arquivística de Documentos (Sigad). Esse Sistema é capaz de manter a relação orgânica entre os documentos e de garantir a confiabilidade, a autenticidade e o acesso aos documentos arquivísticos ao longo do tempo, ou seja, seu valor como fonte de prova das atividades do órgão produtor (CONSELHO NACIONAL DE ARQUIVOS, 2011). O Sigad deve gerenciar, preferencialmente, os documentos arquivísticos digitais em fase corrente e intermediária, já os documentos digitais em fase permanente são dependentes de um bom sistema informatizado que apoie o tratamento técnico adequado, de forma a assegurar a manutenção da autenticidade e da relação orgânica desses documentos (BRASIL, 2015). Para os documentos digitais em fase permanente, utilizam-se os Repositórios Arquivísticos Digitais Confiáveis (RDC-Arqs), que contemplam Arranjo, Descrição, Digitalização, Difusão e Acesso de Documentos de caráter permanente.

Conforme o Conselho Nacional de Arquivos (Conarq) (2011), no fim do século XX, a produção crescente de documentos arquivísticos exclusivamente em formato digital reforçou a necessidade da implantação de programas de gestão arquivística de documentos, pois as organizações e os cidadãos dependem dele como fonte de prova e informação, bem como de garantia de direitos (BRASIL, 2015).

Com o propósito de buscar soluções e desenvolver um modelo de gestão de preservação digital adequado à legislação vigente, que possa contribuir para agilizar e melhorar o desempenho das atividades administrativas, é que este trabalho se configura. Assim, o presente estudo objetiva propor um modelo de gestão de preservação digital de PEAPD da CPAG da UFSM, pois são esses os que apresentam maior número de processos que não foram quitados, sendo, por tal motivo, os mais consultados em busca de informações.

\section{Referencial teórico}


Neste capítulo são expostos os subsídios teóricos considerados essenciais para o embasamento da pesquisa.

\title{
2.1 Documento arquivístico e documento arquivístico digital
}

A apresentação deste item inicia-se com a definição de documento arquivístico (DA), a qual não só o define, como também demonstra suas características, conforme segue:

\begin{abstract}
Os documentos arquivísticos surgem naturalmente no decorrer das atividades de uma pessoa física ou jurídica, como uma decorrência normal do ato de se registrar essas atividades. Desse registro espontâneo resulta uma promessa (grifo nosso) de imparcialidade dos documentos bem como um vínculo entre eles. Tal vínculo se traduz na relação orgânica ${ }^{1}$ que cada documento tem um com o outro e no fato do conjunto documental daí resultante ser dotado de organicidade. Como se trata de documentar atividades, cada documento é único no seu conjunto na medida em que ali desempenha uma função específica. Finalmente, a submissão desses documentos a procedimentos arquivísticos ininterruptos de gestão e de preservação, garante a sua autenticidade. (RONDINELLI, 2011, p. 195).
\end{abstract}

O Modelo de Requisitos para Sistemas Informatizados de Gestão Arquivística de Documentos (e-ARQ Brasil) explica a necessidade de adoção de procedimentos rigorosos de controle para garantir a confiabilidade e a autenticidade dos documentos arquivísticos, bem como o acesso contínuo a eles. Segundo o e-ARQ Brasil, é necessária a implantação de um programa de gestão arquivística de documentos, o qual terá que atender a uma série de exigências, conforme descrito abaixo (CONSELHO NACIONAL DE ARQUIVOS, 2011, p. 16, grifo nosso):

\section{O documento arquivístico deve:}

a) refletir corretamente o que foi comunicado, decidido ou a ação implementada;

b) conter os metadados necessários para documentar a ação;

c) ser capaz de apoiar as atividades;

d) prestar contas das atividades realizadas.

O programa de gestão arquivística de documentos deve: 
a) contemplar o ciclo de vida dos documentos;

b) garantir a acessibilidade dos documentos;

c) manter os documentos em ambiente seguro;

d) reter os documentos somente pelo período estabelecido na tabela de temporalidade e destinação;

e) implementar estratégias de preservação dos documentos desde sua produção e pelo tempo que for necessário;

f) garantir as seguintes qualidades do da - organicidade, unicidade, confiabilidade, autenticidade e acessibilidade.

O Modelo de Requisitos também explica as qualidades que o documento arquivístico deve apresentar, que são: Organicidade, Unicidade, Confiabilidade ou Fidedignidade, Autenticidade e Acessibilidade. Além de tais qualidades, é importante salientar a definição e características dos metadados ${ }^{2}$, os quais são obrigatórios para o DA. Quais sejam:

a) classe - refere-se aos níveis de agregação do plano de classificação, com informações a respeito da temporalidade e da destinação prevista para os documentos nela classificados;

b) documento - refere-se aos DAs que são gerenciados pelo Sigad;

c) componente digital - refere-se aos objetos digitais ${ }^{3}$ que compõem o documento arquivístico digital (DAD). De modo geral, são os arquivos de computador que contêm as informações de conteúdo, forma e composição necessárias à apresentação do DA;

d) evento de gestão - refere-se às ações de gestão que ocorrem com os DAs ao longo de seu ciclo de vida, como captura, tramitação, abertura e encerramento de processo, classificação, desclassificação, eliminação, transferência, recolhimento, entre outros;

e) evento de preservação - refere-se às ações de preservação realizadas nos DADs, tais como migração, compressão, validação, decifração;

f) agente - refere-se aos usuários que acessam o Sigad.

A partir disso, segue-se para a definição de Documento Arquivístico Digital, que é o documento digital reconhecido e tratado como documento arquivístico. É considerado como documento digital toda informação registrada, 
codificada em dígitos binários, acessível e interpretável por meio de sistema computacional (CONSELHO NACIONAL DE ARQUIVOS, 2011).

Uma questão de fundamental importância refere-se às formas de produção do documento digital, visto que influenciam diretamente nos processos de gestão de sua preservação, conforme elucida Innarelli (2015, p. 81):

a) documento nato digital - a produção ocorre diretamente em formato digital por meio de um sistema informatizado ou de um equipamento computacional;

b) documento digitalizado - a produção é feita a partir de um documento convencional por meio de um dispositivo computacional de digitalização, como um escâner.

Destaca-se que ambos são documentos digitais, pois em sua forma final dependem do hardware, do software e do suporte + informação para serem processados e manifestados (INNARELLI, 2015). Segundo Rondinelli (2011), as características do DAD são: forma fixa, conteúdo estável, relação orgânica, contexto identificável, ação e envolvimento de cinco pessoas: autor, redator, destinatário, originador e produtor.

\subsection{Autenticidade do DAD}

A presunção de autenticidade do DAD é realizada por meio da análise da sua forma e do seu conteúdo, bem como do ambiente de produção, manutenção/uso e preservação desse documento. Ela não se dá apenas com base em suas características físicas (suporte e cadeias de bits nele registradas), tampouco em soluções tecnológicas. Isso ocorre porque os DADs são facilmente duplicados, distribuídos, renomeados, reformatados ou convertidos, além de poderem ser alterados e falsificados com facilidade, sem deixar rastros aparentes (BRASIL, 2012).

A Resolução n. 37 do Conarq (BRASIL, 2012), que aprova as diretrizes para a Presunção de Autenticidade de DADs, cita que a autenticidade desse tipo 
de documento deve estar apoiada em procedimentos de gestão arquivística de documentos.

Sendo assim, devem ser implementadas, sempre que possível, técnicas de autenticação apoiadas em políticas e procedimentos administrativos e arquivísticos independentes de tecnologia e/ou neutros. Por outro lado, também podem ser empregadas técnicas de autenticação dependentes de tecnologia, tal como a assinatura digital, as quais são usadas para fornecer um mecanismo tecnológico que declara a autenticidade dos documentos digitais em um dado momento.

É relevante considerar que as técnicas de autenticação baseadas em tecnologia não são efetivas para a transmissão dos documentos no tempo, ou seja, quando são armazenados em longo prazo, ou quando há atualização/substituição de hardware, software ou formatos. Isso significa que, em razão da necessidade de conversões, a assinatura digital não garante a autenticidade do documento em longo prazo, fazendo-se necessários outros procedimentos de gestão e de preservação, como a inserção de metadados (BRASIL, 2012).

Uma vez que existe o risco de falha na autenticação, uma alternativa viável seria a implementação de RDC-Arqs para assegurar a preservação, o acesso e a autenticidade de longo prazo dos materiais digitais, conforme Resolução $n^{\circ} 43$ do Conarq (BRASIL, 2015). É importante destacar que o gerenciamento do documento digital é realizado através da norma mais importante da área: o Open Archival Information System (OAIS), que consiste em um modelo conceitual que descreve as funções de um repositório digital e dos metadados necessários para a preservação e o acesso dos materiais digitais gerenciados pelo repositório (BRASIL, 2015). 


\subsection{GED x SIGAD}

Conforme Flores e Baggio (2013, p. 18), "um sistema de GED usa a tecnologia de informática para captar, armazenar, localizar e gerenciar versões digitais das informações". No entanto, "na abordagem da GED não há tratamento da informação de forma arquivística, ou seja, não é incorporado o ciclo de vida dos documentos [...], nem sua relação orgânica4 [...]" (LAMPERT, 2013, p. 32).

Nesse sentido, o Conarq criou a Câmara Técnica de Documentos Eletrônicos (CTDE), um grupo de trabalho que tem por objetivo definir e apresentar ao Conarq, diretrizes, procedimentos técnicos e instrumentos legais sobre gestão arquivística e preservação dos documentos digitais em conformidade com os padrões nacionais e internacionais.

A CTDE, por sua vez, criou o e-ARQ Brasil - Modelo de Requisitos para Sistemas Informatizados de Gestão Arquivística de Documentos, que se refere a uma especificação de requisitos a serem cumpridos pela organização produtora/recebedora de documentos, pelo sistema de gestão arquivística e pelos próprios documentos, a fim de garantir sua confiabilidade e autenticidade, assim como sua acessibilidade (CONSELHO NACIONAL DE ARQUIVOS, 2011, p. 9).

Ademais, o e-ARQ Brasil especifica todas as atividades e operações técnicas da gestão arquivística de documentos, desde a produção, tramitação, utilização e arquivamento, até a sua destinação final, e indica que todas essas atividades poderão ser desempenhadas por um Sigad (CONSELHO NACIONAL DE ARQUIVOS, 2011).

O Sigad é um sistema desenvolvido para produzir, receber, armazenar, dar acesso e destinar documentos de arquivo digitais. Ele pode compreender um software particular, um determinado número de softwares integrados, adquiridos ou desenvolvidos por encomenda, ou uma combinação desses. Seu sucesso dependerá fundamentalmente da implementação de procedimentos e políticas de gestão de documentos (CONSELHO NACIONAL DE ARQUIVOS, 2011).

Para Levi, (2008, tradução nossa), os sistemas atuais não são suficientes, pois, embora sejam de gerenciamento de ativos digitais ou repositórios digitais 
para gerenciar e armazenar objetos digitais, esses sistemas não são projetados com a preservação do conhecimento digital em mente. Em vez disso, eles enfocam um gerenciamento de acesso ou facilitam o dia a dia do conteúdo digital pelos usuários.

\subsection{Preservação digital}

Como documentos arquivísticos são produzidos em grande escala por organizações públicas e privadas, destaca-se que, em 2008, Levi (tradução nossa) já alertava para o volume substancial de informações digitais perdidas e convocava a todos a realizarem a preservação da informação digital, tendo em vista que o ritmo das perdas de ativos importantes aumentaria diariamente.

Ferreira (2006, p. 12) define preservação digital como "a atividade que garante que a comunicação entre um emissor e um receptor é possível, não só através do espaço, como também através do tempo". Por outro lado, esse autor considera que, no contexto digital, a preservação do suporte ou da sequência de its que constitui o objeto não é condição suficiente para garantir que a informação permaneça acessível, reutilizável e autêntica ao longo do tempo.

Para Levi (2008), a preservação digital tem a ver com garantir a usabilidade futura de uma acessibilidade ao conteúdo digital. Tal informação é corroborada por Flores e Hedlund quando declaram que "[...] a preservação de documentos tem por objetivo assegurar a integridade, autenticidade e acessibilidade, a longo prazo, dos suportes documentais e da informação contida neles." (FLORES; HEDLUND, 2014, p. 7). Além disso, esses autores ressaltam que o "[...] acesso aos documentos armazenados deve estar firmado em descrições sólidas e consistentes, regido pelos princípios arquivísticos." (FLORES; HEDLUND, 2014, p. 7)

Conforme o e-ARQ Brasil (CONSELHO NACIONAL DE ARQUIVOS, 2011), o foco da preservação de documentos arquivísticos, no caso dos documentos digitais, é a manutenção do acesso, que pode implicar mudança de suporte e formato, bem como atualização do ambiente tecnológico. Nesse sentido, Zazo e Cáceres (2017) afirmam que as particularidades dos documentos 
digitais são tão significativas que levam ao desenvolvimento de técnicas específicas de gestão, tratamento e conservação adaptadas às novas necessidades oriundas do desenvolvimento tecnológico dos meios existentes para a criação, disseminação e uso de documentos.

O Modelo de Requisitos para a Gestão de Arquivos Eletrônicos (MoReq) também cita, como medida de preservação recomendável e necessária, a adoção de formatos digitais abertos e indica que as estratégias de preservação de documentos digitais e dos respectivos metadados sejam formuladas e integradas ao Sigad desde a fase de elaboração do projeto do sistema (CONSELHO NACIONAL DE ARQUIVOS, 2011).

A partir das definições e objetivos citados, pode-se evidenciar a necessidade de políticas claras de preservação por parte da gestão, bem como a definição das estratégias que serão adotadas para sua concretização. Desse modo, as estratégias comumente utilizadas para evitar os riscos provenientes da obsolescência tecnológica e da degradação do suporte são: Preservação da tecnologia; Refrescamento; Emulação; Conversão de dados; Atualização (refreshing); Conversão; Encapsulamento e Migração.

A estratégia descrita nesse estudo será a de Migração. A opção por se utilizar essa estratégia no Modelo proposto deveu-se ao fato de o projeto InterPARES a destacar como uma das principais técnicas de preservação digital adotada para a preservação dos DADs.

\subsubsection{Migração}

A migração para novos sistemas é realizada no caso de obsolescência de hardware, software ou formatos. Envolve, inclusive, conversão de dados. Ela pode abranger grande quantidade de elementos - hardware, software e formatos - e, assim, apresentar maior complexidade de planejamento e execução. Apesar disso, mostra-se como uma alternativa interessante para o acompanhamento das mudanças decorrentes da evolução tecnológica. A migração, assim como a emulação e a conversão de dados, apresenta riscos quanto à integridade e funcionalidade dos documentos arquivísticos digitais, por isso deve ser realizada 
de modo criterioso e sistemático (CONSELHO NACIONAL DE ARQUIVOS, 2011).

Ferreira (2006) considera que, ao contrário das estratégias de Preservação da Tecnologia, Refrescamento e Emulação, que procuram cristalizar o objeto digital no seu formato original, as estratégias baseadas em migração centram-se, sobretudo, na preservação do seu conteúdo intelectual, ou seja, na preservação do objeto conceitual. Esse autor cita como desvantagem, uma grande probabilidade de algumas das propriedades que constituem os objetos digitais não serem corretamente transferidas para o formato de destino adotado. Isso se deve à possibilidade de haver incompatibilidades entre os formatos de origem e destino ou à utilização de conversores incapazes de realizar as suas tarefas adequadamente.

\subsection{Repositórios arquivísticos digitais}

Com vistas a atender às necessidades de criação de repositórios, as instâncias governamentais estabeleceram regras para a gestão e disponibilização de dados para acesso aberto e contínuo. Esse é o caso da Resolução nº 43/2015, que altera a Resolução 39 do Conarq, a qual aprova as Diretrizes para a implementação de RDC-Arqs e recomenda sua adoção aos órgãos e entidades integrantes do Sistema Nacional de Arquivos (SINAR) para o arquivamento e manutenção dos documentos arquivísticos em formato digital, além de garantir a autenticidade, a confidencialidade, a disponibilidade e a preservação desses documentos (BRASIL, 2015).

Destaca-se, por meio das diretrizes do RDC-Arq, que os documentos arquivísticos digitais em fase corrente e intermediária devem, preferencialmente, ser gerenciados por meio de um SIGAD. No entanto, como ocorre uma alteração na cadeia de custódia a partir da destinação desses documentos para guarda permanente, a responsabilidade por sua preservação passa para a instância de guarda.

A implantação de um repositório digital confiável é fundamental para assegurar a preservação, o acesso e a autenticidade dos materiais digitais em 
longo prazo. Nesse sentido, o gerenciamento do documento digital é realizado através da norma mais importante da área: o Open Archival Information System (OAIS). Trata-se de um modelo conceitual que descreve as funções de um repositório digital e os metadados necessários para a preservação e o acesso dos materiais digitais gerenciados pelo repositório, que constituem um modelo funcional e um modelo de informação (BRASIL, 2015).

Embora o modelo OAIS seja constituído de uma estrutura teórica e conceitual projetada para viabilizar o acesso a documentos digitais no futuro, Zazo e Cáceres (2017) destacam que sua mera aplicação para criar um repositório não garante o uso futuro dos documentos digitais nele contidos. Isso porque, para tais autores, um repositório digital é uma entidade viva, criada com uma vocação de permanência, que exige uma revisão constante de suas práticas.

Considerando-se que os documentos digitais em fase permanente dependem de um RDC-Arq para o tratamento técnico adequado dos documentos, o Modelo proposto para este estudo irá adotar o Archivematica, que é um software livre para criação de repositórios digitais, desenvolvido em código aberto e com acesso ao código fonte, criado pela empresa Artefactual System.

Segundo Flores e Hedlund (2014), o software Archivematica, é um repositório digital destinado a armazenar a documentação digital de acordo com os padrões exigidos em relação à preservação digital, visando torná-la acessível a longo prazo. Destaca-se, conforme informações encontradas no sítio desse repositório, que o Archivematica usa um padrão de design de micro serviços para fornecer um conjunto integrado de ferramentas de software que permite ao usuário processar objetos digitais, desde o ingresso até o acesso, em conformidade com o modelo funcional OAIS, a norma mais importante da área. 


\subsection{Gerenciamento do documento digital}

Conforme o Conarq (BRASIL, 2015), o gerenciamento dos documentos de um repositório digital confiável deve estar de acordo com o modelo de referência $O A I S$, que estabelece a formação de pacotes de informação envolvendo os documentos digitais (informação de conteúdo) e seus metadados (informação de representação).

Um repositório que segue a norma OAIS é constituído por pessoas e sistemas com a responsabilidade de preservar a informação e torná-la disponível. O ambiente do modelo conta com três entidades externas:

a) produtor - pessoas ou sistemas que fornecem a informação a ser preservada.

b) administrador - aqueles que estabelecem as políticas gerais que governam o repositório.

c) consumidor - pessoas ou sistemas que interagem com os serviços OAIS para acessar a informação preservada desejada.

O repositório definido para o estudo, no caso o Archivematica, utiliza basicamente três etapas distintas dentro do repositório:

a) SIP (submission information package) - pacote de informação para submissão: refere-se à admissão dos documentos digitais e seus metadados associados, e armazenamento dos documentos digitais e seus metadados associados;

b) DIP (dissemination information package) - pacote de informação para disseminação: refere-se ao acesso aos documentos;

c) AIP (archival information package) - pacote de informação para arquivamento: refere-se ao acondicionamento e armazenamento dos digitais e seus metadados associados (BRASIL, 2015, p. 13). 


\section{Metodologia}

Esta pesquisa caracteriza-se pela natureza aplicada, cuja finalidade é gerar conhecimentos para uso prático, com vistas à solução de um problema específico, que vem a ser a preservação digital, a longo prazo, dos PEAPD. Com relação à abordagem do problema, foi realizada uma pesquisa quali-quantitativa, tal combinação se deve ao intuito de fornecer um quadro geral da questão em estudo. Nesse sentido, foi realizada tanto a análise e a caracterização do PEAPD, como sua medida, ou seja, a quantidade desses processos, através da pesquisa de documentos referentes a esses mesmos processos.

No que diz respeito ao seu objetivo, a pesquisa foi descritiva, pois visou descrever as características dos processos de exercícios anteriores (PEAs), por meio de um levantamento de dados. Em relação aos procedimentos técnicos, foram empreendidos 3 tipos de pesquisa: bibliográfica, documental e, ainda, uma pesquisa-ação, já que sua realização soluciona um problema coletivo, e tanto os pesquisadores quanto os participantes representativos da situação estão diretamente envolvidos.

Para a operacionalização do trabalho, foi selecionada uma amostra nãoprobabilística intencional ou de seleção racional. Por fim, devido ao número elevado de PEAs, optou-se por utilizar como modelo o processo de progressão funcional docente. Tal opção deve-se ao fato desses processos serem os mais procurados pelos professores em busca de informações, já que são esses os que possuem o maior número de processos ainda não quitados.

\section{Análise dos resultados dos procedimentos metodológicos}

Inicialmente, realizou-se um diagnóstico referente ao interstício de 2010 a 2016, com vistas a identificar a quantidade de PEAs existentes na CPAG, diferenciando-os por assunto e valores, em seu contexto de produção e arquivamento. Foram identificados 35 assuntos de PEA. Nesse sentido, para a análise, os processos foram divididos em PEA quitados e PEA não quitados e foram elencados em ordem crescente do montante a que equivalem, como demonstram as Tabelas 1 e 2 respectivamente: 
Tabela 1 - Demonstrativo de PEA quitados

\begin{tabular}{ccc}
\multicolumn{3}{c}{ PEA Quitados } \\
\hline Assunto & Quantidade & Valor \\
\hline Adicional plantão hospitalar & 393 & $333.842,02$ \\
\hline Abono de permanência & 117 & $556.210,60$ \\
\hline Progressão funcional & 693 & $871.480,46$
\end{tabular}

Fonte: Elaborado pelos autores.

Tabela 2 - Demonstrativo de PEA não quitados

\begin{tabular}{|ccc|}
\hline \multicolumn{3}{c}{ PEA Não Quitados } \\
\hline Assunto & Quantidade & Valor \\
\hline Abono de permanência & 73 & $1.183 .203,90$ \\
\hline Progressão funcional & 244 & $2.722 .725,97$ \\
\hline Retribuição por titulação & 67 & $5.315 .941,86$ \\
\hline
\end{tabular}

Fonte: Elaborado pelos autores.

Identificou-se, a partir da análise, que o processo de progressão funcional representa tanto a maior quantidade, quanto o maior valor financeiro de processos já quitados, fatos que vêm a justificar a escolha do referido assunto como base do presente estudo.

No que tange aos PEA não quitados, o maior montante é o dos processos de Retribuição por Titulação (RT), totalizando o valor de R $\$$ 5.315.941,86, com 67 processos. Quando se compara a quantidade desse tipo de processo ao de Progressão Funcional (PF), que possui o segundo maior quantitativo (244), temse que: o processo de RT equivale a $27,46 \%$ da quantidade do processo de PF, ou seja, um valor baixo comparativamente. Deve-se considerar, ainda, que o processo de $\mathrm{PF}$ equivale ao valor de $\mathrm{R} \$ 2.722 .725,97$, ou seja, mais da metade do maior montante (processo de RT), contendo, ainda, o segundo maior quantitativo de processos, totalizando 244 processos não quitados.

O primeiro maior quantitativo, que equivale a 344 processos, é o de Gratificação Natalina. Esse quantitativo não aparece na tabela que demonstra apenas os maiores montantes por não ter sido levado em consideração devido a sua peculiaridade de se referir a diversos assuntos.

A segunda etapa da pesquisa caracterizou-se pela análise dos processos, diplomaticamente, em seu contexto de produção e arquivamento, visando 
subsidiar a elaboração de um modelo de gestão de longo prazo, executada através da elaboração da Tabela de Temporalidade dos processos, existente na CPAG. Devido ao extenso volume de informações que esta tabela apresenta, será exibida apenas a classificação da parte onde consta o assunto progressão funcional, objeto desse estudo. A tabela foi elaborada com base na Classificação, Temporalidade e Destinação de Documentos de Arquivo Relativos às Atividades-Meio da Administração Pública, conforme pode ser observado na Tabela 3:

Tabela 3 - Temporalidade e classificação documental dos PEAs do período de 2010-2016

\begin{tabular}{|c|c|c|c|c|c|c|}
\hline \multicolumn{7}{|c|}{000 ADMINISTRAÇÃO GERAL } \\
\hline \multicolumn{7}{|l|}{020 PESSOAL } \\
\hline \multicolumn{7}{|c|}{023 QUADROS, TABELAS E POLÍTICA DE PESSOAL } \\
\hline \multirow[b]{2}{*}{ CLASSIFICAÇÃO } & \multirow[b]{2}{*}{ ASSUNTO } & \multirow[b]{2}{*}{$\begin{array}{l}\text { QUANTI- } \\
\text { DADE }\end{array}$} & \multicolumn{2}{|c|}{$\begin{array}{c}\text { PRAZO DE } \\
\text { GUARDA }\end{array}$} & \multirow{2}{*}{$\begin{array}{c}\text { DESTINA- } \\
\text { ÇÃO } \\
\text { FINAL }\end{array}$} & \multirow[b]{2}{*}{ OBS. } \\
\hline & & & $\begin{array}{c}\text { FASE } \\
\text { COR- } \\
\text { RENTE }\end{array}$ & $\begin{array}{c}\text { FASE } \\
\text { INTERME- } \\
\text { DIÁRIA }\end{array}$ & & \\
\hline \multirow{6}{*}{$\begin{array}{l}023.03 \\
\text { REESTRUTURAÇÕES E } \\
\text { ALTERAÇÕES } \\
\text { SALARIAIS } \\
\text { ASCENSÃO E } \\
\text { PROGRESSÃO } \\
\text { FUNCIONAL } \\
\text { AVALIAÇÃO DE } \\
\text { DESEMPENHO } \\
\text { ENQUADRA-MENTO } \\
\text { EQUIPARAÇÃOREAJUSTE } \\
\text { E REPOSIÇÃO SALARIAL } \\
\text { PROMOÇÕES }\end{array}$} & $\begin{array}{c}\text { Incentivo à } \\
\text { Qualificação }\end{array}$ & 257 & 5 & 47 & Eliminação & \\
\hline & $\begin{array}{c}\text { Progressão } \\
\text { Funcional }\end{array}$ & 940 & 5 & 47 & Eliminação & \\
\hline & $\begin{array}{c}\text { Progressão } \\
\text { por } \\
\text { Capacitação }\end{array}$ & 406 & 5 & 47 & Eliminação & \\
\hline & & & & & & \\
\hline & $\begin{array}{l}\text { Progressão } \\
\text { por Mérito }\end{array}$ & 564 & 5 & 47 & Eliminação & \\
\hline & $\begin{array}{c}\text { Retribuição } \\
\text { por } \\
\text { Titulação }\end{array}$ & 70 & 5 & 47 & Eliminação & \\
\hline
\end{tabular}

Fonte: Conselho Nacional de Arquivos (2001).

A observação do Tabela 3, na íntegra, revela que mais da metade dos processos distribuídos nas Classes/Subclasses/Grupos e Subgrupos, mais precisamente $56,67 \%$ deles, devem permanecer 5 anos na fase corrente e 47 na intermediária. Isso significa que o processo de PF deve permanecer 5 anos em local de fácil acesso, por ser um documento frequentemente consultado. Além 
disso, deve ser arquivado por 47 anos em outro local, mas por ser um documento ainda necessário à administração, ainda que pouco usado, deve permanecer à disposição do órgão produtor.

$\mathrm{Na}$ terceira etapa da pesquisa, realizou-se o mapeamento do PEAPD, desenhando o seu fluxograma com a finalidade de demonstrar o fluxo desse processo desde o início de sua criação até o seu arquivamento, o qual ocorre caso não existam valores de exercícios anteriores a serem restituídos. Se houverem valores a restituir, um novo processo referente ao assunto em questão, denominado "processo de exercícios anteriores", deverá ser aberto, como demonstra a Figura 1, a seguir: 
Crislei Daiana Oliveira Siqueira Schuch, Denise de Souza Saad e Daniel Flores

Figura 1 - Fluxograma de processo de exercícios anteriores de progressão funcional docente

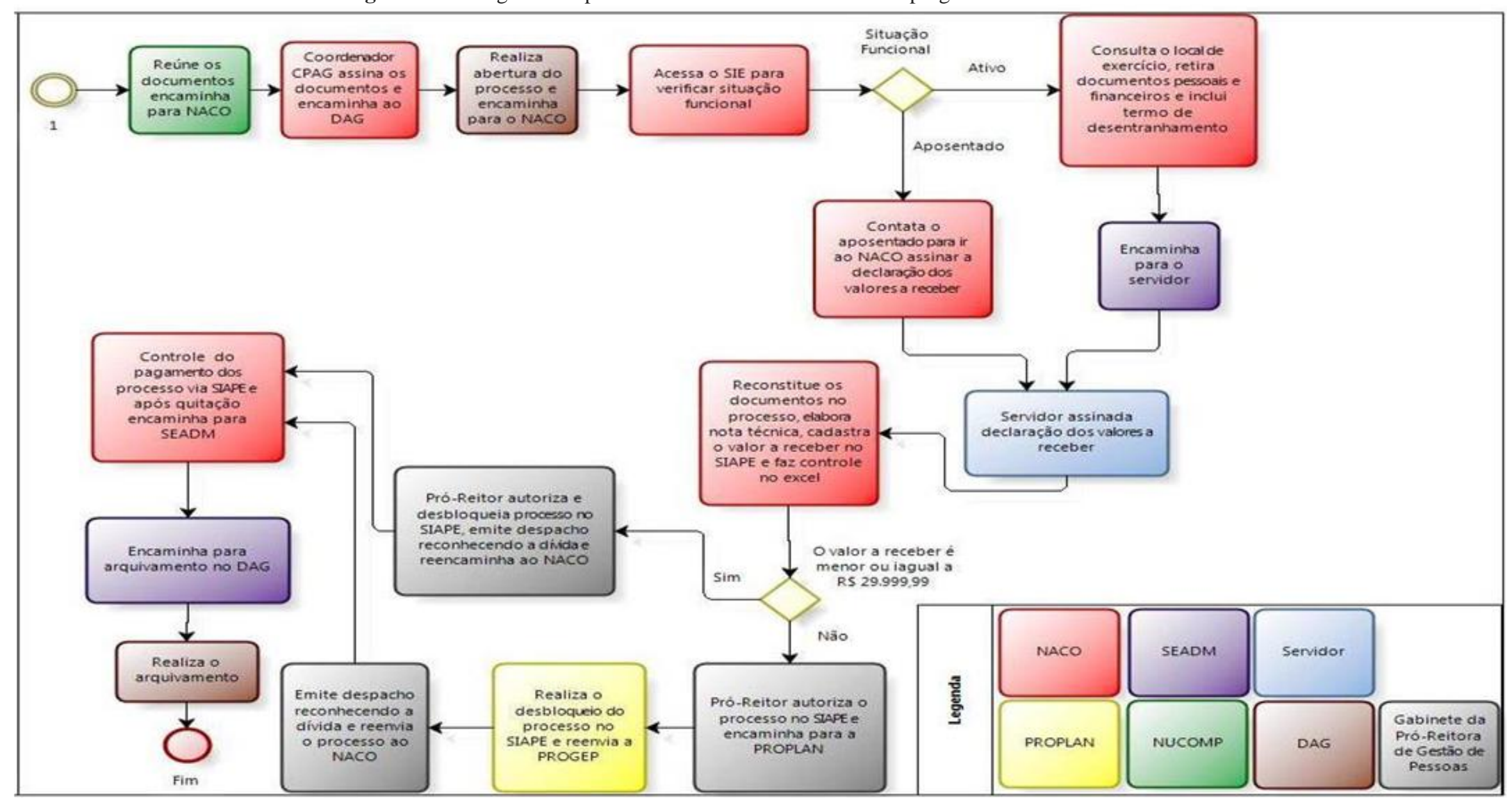

Fonte: Elaborado pelos autores. 
Crislei Daiana Oliveira Siqueira Schuch, Denise de Souza Saad e Daniel Flores

A quarta e última etapa da pesquisa foi a de propor o modelo de gestão de preservação digital dos PEAPD em longo prazo, contemplando desde a sua produção até a sua locação final em uma Cadeia de Custódia. A Figura 2 apresenta o fluxo do Modelo proposto e, a seguir, são explicitadas suas principais funções.

Figura 2 - Modelo de Gestão de Preservação digital dos PEAPD

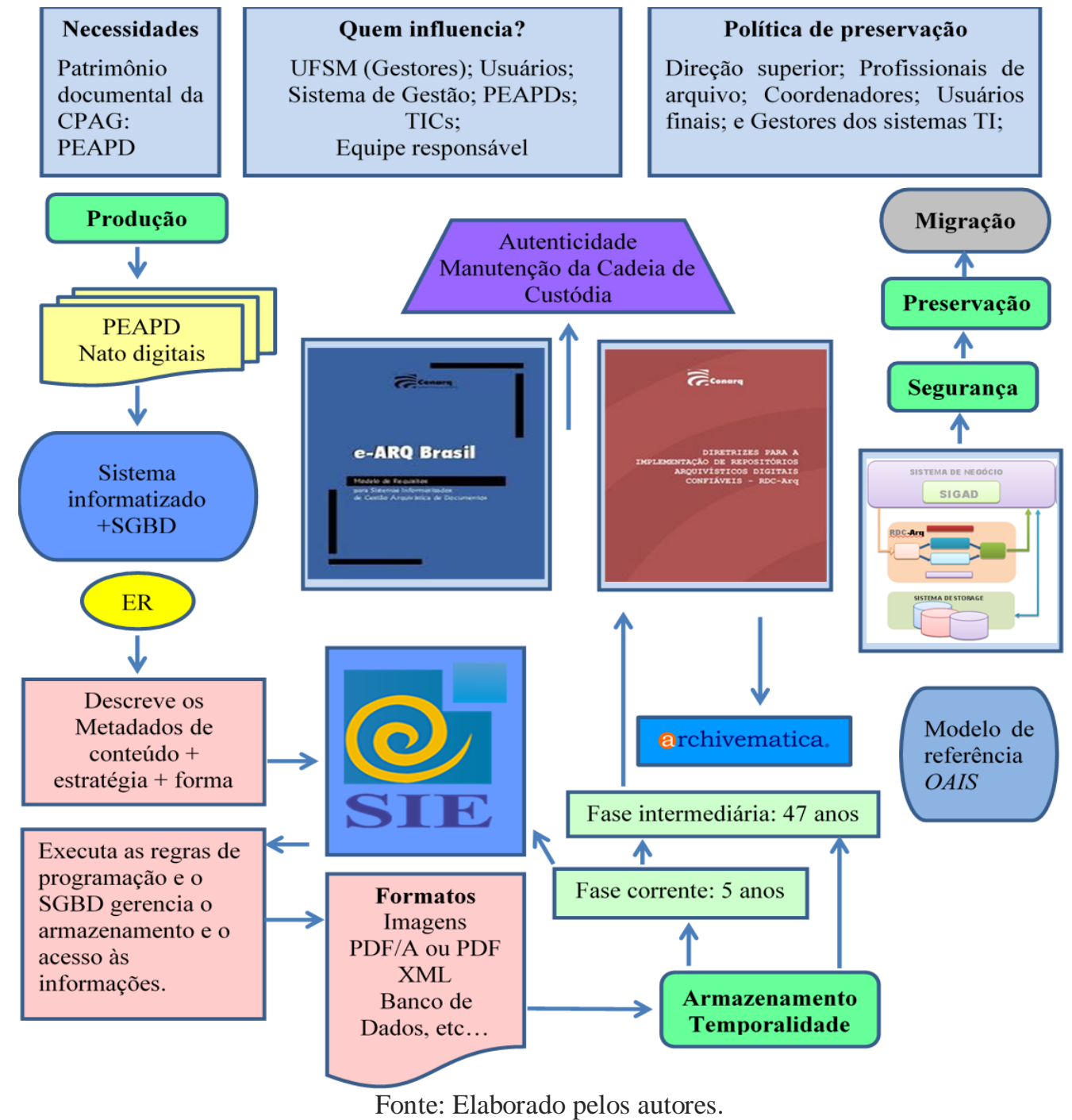

A parte superior do modelo apresenta as Necessidades, o que remete à definição dos documentos a serem preservados: os PEAPDs. Apresenta também as pessoas e sistemas que influenciam a preservação, quais sejam: a UFSM, na figura do dirigente máximo (o reitor), bem como os demais responsáveis pela gestão; os usuários, que são todos que utilizam o sistema de gestão de 
preservação digital, seja na produção ou inclusão dos documentos, seja para acesso; o sistema de gestão, que vem a ser o SIE (que utiliza um SGBD Sistema de Gestão de Banco de Dados) com as funcionalidades do Sigad; os documentos, que são os PEAPDs; as tecnologias de informação (TICs), que podem interferir no modelo como um todo, através das mudanças e inovações tecnológicas de hardware e software, as quais exigem que o Sistema de Gestão se adeque a elas; por fim, a equipe responsável (ER), que são as pessoas responsáveis por realizarem o processo de preservação digital.

O terceiro item da parte superior do modelo refere-se à política de preservação, na qual a UFSM deve definir uma política de gestão arquivística de documentos que tenha por objetivo produzir, manter e preservar documentos confiáveis, autênticos, acessíveis e compreensíveis, de maneira a apoiar suas funções e atividades. Tal política deve explicitar as responsabilidades e designar as autoridades envolvidas no programa de gestão. Dessa forma, é fundamental que todos os servidores estejam envolvidos.

A partir disso, inicia-se o fluxo do modelo com a Produção dos documentos arquivísticos digitais através de sistemas informatizados e SGBD, visto que a ideia é criar documentos nato digitais, utilizando o sistema SIE da UFSM como apoio.

O SIE será utilizado por ser um sistema de gestão acadêmica e administrativa informatizado que utiliza um SGBD - o IBM/DB2 - bem como por estar sendo adequado para ser também um Sigad. Além disso, o projeto GEDAI $^{5}$ da UFSM já desenvolveu um Modelo Conceitual que vem sendo utilizado para a produção dos Diários de Classe da própria universidade, em que o SIE incorpora as funcionalidades de um Sigad e interopera com um RDC-Arq, produzindo documentos nato digitais (KROTH et al., 2017). Sendo assim, a ideia é que os metadados sejam adequados para serem implantados no Modelo dos PEAPD aqui proposto.

A ER, especialmente bibliotecários e arquivistas, tem a função de descrever os documentos digitais por meio de metadados, como, por exemplo, número identificador, título e código. A descrição do objeto digital por metadados tem três fases: a descrição inicial relativa ao seu conteúdo, quando o 
objeto é transferido para a custódia da IES; a descrição das estratégias de preservação aplicadas ao objeto durante seu ciclo de vida, registrando todas as transformações ocorridas e criando garantias para sua autenticidade; e, por fim, a descrição da forma pela qual o objeto digital foi descartado (GRÁCIO, 2011).

A produção dos documentos arquivísticos digitais depende das regras implementadas nos sistemas informatizados e dos SGBD. Essa produção apresenta os seguintes formatos de documentos: Imagens; PDF/A ou PDF; XML; Banco de dados; e Sistemas híbridos (INNARELLI, 2015).

Após a produção do documento, o fluxo parte para o armazenamento desses documentos, considerando os prazos estipulados na tabela de temporalidade. $\mathrm{O}$ armazenamento tem como objetivo inserir o objeto digital no sistema de gestão, garantindo a autenticidade, a busca, a recuperação e o acesso aos documentos pelo tempo estipulado na tabela de temporalidade e destinação.

O SIE, operando com as funcionalidades de um Sigad, deve identificar a temporalidade e a destinação previstas para os PEAPD no momento da captura e do registro, de acordo com os prazos e ações estabelecidos na tabela de temporalidade. Tal informação deve ser registrada em um metadado associado ao documento.

No que tange aos PEAPD, a tabela de temporalidade determina o prazo de guarda de 5 anos em fase corrente e 47 anos em fase intermediária. No entanto, considera-se, nesse caso, fase intermediária somente o período após a quitação dos processos, ou seja, o prazo de 47 anos só começará a contar a partir da quitação do processo. Na fase corrente, então, os PEAPDs ficam armazenados no SIE, que opera com a as funcionalidades de um Sigad. Após finalizada essa fase, deve ser executada a transferência dos documentos para o arquivo intermediário, que vem a ser o RDC-Arq, onde aguardarão o cumprimento dos prazos de guarda e a destinação final.

Tal processo deve ocorrer porque as diretrizes aprovadas pela Resolução $n^{\circ} 39 / 2014$ do Conarq determinam que a preservação dos documentos arquivísticos digitais, nas idades corrente, intermediária e permanente, deve estar associada a um repositório digital confiável. Dessa forma, os arquivos 
devem dispor de repositórios digitais confiáveis para a gestão, a preservação e o acesso de documentos digitais.

Ressalta-se que o gerenciamento de documentos feito pelo RDC-Arq não deve ser confundido com a gestão documental realizada pelo Sigad. Enquanto o RDC-Arq gerencia aspectos como o armazenamento seguro e a aplicação sistemática de estratégias de preservação, o Sigad faz a gestão arquivística dos documentos (CONSELHO NACIONAL DE ARQUIVOS, 2015).

O presente modelo utiliza o Cenário 3, conforme sugere a Orientação Técnica ${ }^{\circ} 3$ do Conarq, referente aos Cenários de uso de RDC-Arq em conjunto com o Sigad, onde um sistema informatizado de processos de negócio no ambiente do produtor incorpora as funcionalidades de um Sigad e interopera com um RDC-Arq e/ou um sistema de storage.

A seleção desse cenário deveu-se ao fato de o sistema de gestão da UFSM, o SIE, atuar com as funcionalidades de um Sigad e interoperar com um RDC-Arq. O modelo de RDC-Arq adotado é o Archivematica, que é um software livre, de código aberto e está em conformidade com o modelo de referências OAIS (KROTH et al., 2017).

A partir disso, o fluxo segue para a Segurança, onde precisam ser realizados: os controles de acesso aos documentos; os registros de uso desses documentos pelos usuários (que devem ser registrados pelo sistema nos seus respectivos metadados); e, por fim, as cópias de segurança realizadas pelo SIE, através de backups periódicos das informações, com o propósito de restauração posterior, em caso de perda devido a falhas de software, hardware ou mesmo acidentes.

O próximo item do fluxo refere-se à preservação dos documentos digitais, cujo foco é a manutenção do acesso, que pode implicar mudança de suporte e formato, bem como atualização do ambiente tecnológico. Para garantir a autenticidade e acessibilidade, assim como evitar os riscos provenientes da obsolescência tecnológica e da degradação do suporte, a UFSM necessita dispor de procedimentos de migração, utilizando-se das estratégias de preservação de documentos digitais. 
Para finalizar, o fluxo termina na estratégia sugerida para o Modelo, que é a estratégia de Migração. Essa estratégia é destacada pelo projeto InterPARES como uma das principais técnicas de preservação digital adotadas para a preservação dos documentos arquivísticos digitais.

\section{Considerações finais}

O impacto das grandes transformações e as possibilidades de riscos advindos das tecnologias da informação sobre os documentos leva os profissionais de arquivo, e os gestores como um todo, a atentarem para o processo de conversão da forma como a manutenção do acervo da organização vem sendo realizada.

No decorrer da pesquisa, contatou-se que os documentos devem ser nato digitais, produzidos em uma cadeia de custódia, ou seja, os documentos arquivísticos devem ser elaborados diretamente em formato digital por meio do sistema informatizado. A produção massiva desses documentos, por sua vez, deve estar fundamentada nos preceitos arquivísticos, desde a produção do documento até a sua destinação final, de forma a garantir o seu acesso no presente e no futuro.

É importante destacar que a preservação de documentos deve estar associada a um repositório arquivístico digital confiável, visto que a custódia, exercida por uma entidade independente, possibilita que o documento arquivístico digital seja preservado sem ter sua autenticidade ameaçada, seja pela obsolescência tecnológica, pela degradação de suporte ou por intervenções não autorizadas, que podem ocasionar danos ao documento, alterando-o significativamente.

A existência dos riscos mencionados corrobora a necessidade de se implementar o modelo aqui proposto, visto que apresenta as ferramentas necessárias para se manter a autenticidade dos objetos digitais, utilizando-se do Sistema de Gestão em conjunto com um RDC-Arq. A junção do SIE (com as funcionalidades de um Sigad), que é um sistema informatizado confiável e seguro, com um RDC-Arq possibilita que se atinja a presunção de autenticidade 
do documento arquivístico, a partir do cumprimento dos fatores e procedimentos por ela exigidos.

Para finalizar, é importante destacar a necessidade de políticas claras de preservação por parte da gestão, bem como a definição das estratégias que serão adotadas para sua concretização, como é o caso da Comissão de Estudos para Gestão, Preservação e Acesso aos Documentos Arquivísticos Digitais da UFSM (Gedai).

Somado a isso, deve-se implantar programas de Auditoria e Certificação dos RDC-Arq, tal como o TRAC - Trustworthy Repository Audit \& Certification: Criteria and Checklist (Certificação e auditoria de repositórios confiáveis: critérios e checklist). Tal documento apresenta um conjunto de critérios e um checklist a serem tomados como referência para a certificação de repositórios digitais confiáveis (BRASIL, 2015). Essas medidas devem ser tomadas como forma de garantir a longevidade dos Repositórios Digitais ao longo do tempo, na tentativa de se evitar a perda de dados ou informações.

\section{Referências}

ARQUIVO NACIONAL. Ministério da Justiça. SIGA. Brasília, 2016.

BRASIL. Lei $\mathbf{n}^{\circ} \mathbf{1 2 . 5 2 7}$, de 18 de novembro de 2011. Regula o acesso a informações previsto no inciso XXXIII do art. $5^{\circ}$, no inciso II do $\S 3^{\circ}$ do art. 37 e no $\S 2^{\underline{0}}$ do art. 216 da Constituição Federal. Diário Oficial [da] União, Brasília, 18 nov. 2011.

BRASIL. Ministério da Justiça. Conselho Nacional de Arquivos. Resolução 37, de 19 de dezembro de 2012. Aprova as Diretrizes para a Presunção de Autenticidade de Documentos Arquivísticos Digitais. Rio de Janeiro: Ministério da Justiça, 20 dez. 2012.

BRASIL. Ministério da Justiça. Conselho Nacional de Arquivos. Resolução 43, de 04 de setembro de 2015. Altera a redação da Resolução do CONARQ no 39 , de 29 de abril de 2014, que estabelece diretrizes para a implementação de repositórios digitais confiáveis para a transferência e recolhimento de documentos arquivísticos digitais para instituições arquivísticas dos órgãos e entidades integrantes do Sistema Nacional de Arquivos - SINAR. Rio de Janeiro, 8 set. 2015. 
CONSELHO NACIONAL DE ARQUIVOS. Classificação, temporalidade e destinação de documentos de arquivo relativos às atividades-meio da administração pública. Rio de Janeiro: Arquivo Nacional, 2001.

CONSELHO NACIONAL DE ARQUIVOS. e-ARQ Brasil: modelo de requisitos para sistemas informatizados de gestão arquivística de documentos (MoReq). Câmara Técnica de Documentos Eletrônicos. Rio de Janeiro: Arquivo Nacional, 2011.

CONSELHO NACIONAL DE ARQUIVOS. Câmara Técnica de Documentos Eletrônicos. Cenários de uso de RDC-Arq em conjunto com o SIGAD. Orientação Técnica nº 3. 2015.

CONSELHO NACIONAL DE ARQUIVOS. Câmara Técnica de Documentos Eletrônicos. Glossário documentos arquivísticos digitais. 2016. Versão 7.

FERREIRA, M. Introdução à preservação digital: conceitos, estratégias e actuais consensos. Braga: Escola de Engenharia da Universidade do Minho, 2006.

FLORES, D.; BAGGIO, C. C. Documentos digitais: preservação e estratégias. Biblos: Revista do Instituto de Ciências Humanas e da Informação, Rio Grande, v. 27, n. 1, p. 11-24, jan./jun. 2013.

FLORES, D.; HEDLUND, D. C. A preservação do patrimônio documental através da produção de instrumentos de pesquisa arquivísticos e da implementação de repositórios arquivísticos digitais. Série Patrimônio Cultural e Extensão Universitária, Brasília, n. 3, fev. 2014.

GRÁCIO, J. C. A. Preservação digital na gestão da informação: um modelo processual para as instituições de ensino superior. 2011. Tese (Doutorado em Ciência da Informação) - Programa de Pós-Graduação em Ciência da Informação, Universidade Estadual Paulista "Júlio de Mesquita Filho", Marília, 2011.

INNARELLI, H. C. Gestão da preservação de documentos arquivísticos digitais: proposta de um modelo conceitual. 2015. Tese (Doutorado em Ciência da Informação) - Escola de Comunicações e Artes da Universidade de São Paulo, São Paulo, 2015.

KEISER, B. E. The latest digital preservation projects. Information Today, Washington, DC, Oct. 2017.

KROTH, M. L. et al. Construindo documentos arquivísticos digitais autênticos. In: SEMANA DO SERVIDOR PÚBLICO e II SIMPÓSIO EM GESTÃO PÚBLICA, 18, 2017, Santa Maria. Anais [...]. Santa Maria, 2017. p. 10. 


\title{
LAMPERT, S. R. Repositório Digital Para o Patrimônio Arquivístico
}

Documental: Subsídio para acesso e Preservação do Diário de Classe. 2013. Dissertação (Mestrado em Patrimônio Cultural) - Universidade Federal de Santa Maria, Santa Maria, 2013.

LEVI, Y. Digital preservation: an ever-growing challenge. Information Today, Nova Jersey, Sept. 2008.

PINOCHET, L. H. C. Tecnologia da informação e comunicação. Rio de Janeiro: Elsevier, 2014.

RONDINELLI, R. C. $O$ conceito de documento arquivístico frente à realidade digital: uma revisitação necessária. 2011. Tese (Doutorado em Ciência da Informação) - Universidade Federal Fluminense, Niterói, 2011.

SAAD, B. Estratégias 2.0 para a mídia digital: internet, informação e comunicação. 2.ed.São Paulo: Editora Senac, , 2003.

SANTOS, F. C.; CHARÃO, A. S.; FLORES, D. Análise de Produtos Para Gerenciamento Eletrônico de Documentos. In: SEMINÁRIO DE BIBLIOTECAS UNIVERSITÁRIAS DO NORDESTE, 2., 2002, Bahia. Anais [...]. Salvador: CINFORM, 2003. p. 1.

UNIVERSIDADE FEDERAL DE SANTA MARIA. GEDAI. Santa Maria, 2015.

ZAZO, J. L. B.; CÁCERES, M. D. P. O. L. Criterios de certificación y auditoría de repositorios digitales seguros en archivos. In: Nelson Vaquinhas; Marisa Caixas; Helena Vinagre. (org.). Da produção à preservação informacional: desafios e oportunidades. Évora: Publicações do Cidehus, 2017. p. 529-550.

\section{Digital Preservation in the management of administrative processes of a Higher Education Institution: the case of PEAPDs from PROGEP of UFSM}

\begin{abstract}
It is known that the evolution of information technology has been accompanied by the increase of its importance for the organizations. Thus, this study sought to propose a long-term digital preservation management model of the administrative processes of previous years of Teaching Progression of the Pro-Rectory of People Management of the Federal University of Santa Maria, to enable that these processes are created in the future in digital format and preserved in reliable digital archival repositories. For that, an applied research of was carried out, with a qualitative-quantitative approach to the research problem. Regarding the objectives, the research was descriptive. The results demonstrated that the objective of the study was fulfilled, as the Digital Preservation Management Model was developed, adapted to maintain the chain
\end{abstract}


of custody and the authenticity of the documents of the administrative processes of previous years of Teaching Progression

. In the future, the documents may be produced digitally, in the Information System for Teaching.

Keywords: Digital preservation. Digital archival document. Authenticity. Information and communication technology. Federal University of Santa Maria.

Recebido: 04/05/2018

Aceito:05/10/2018

1 Relação orgânica é a relação que os documentos que participam de uma mesma ação possuem entre si. Ela pode ser expressa por meio do código de classificação, do NUP - Número Único de Protocolo, do número de matrícula, entre outros (ARQUIVO NACIONAL, 2016).

2 Metadados são dados estruturados que descrevem e permitem encontrar, gerenciar, compreender e/ou preservar documentos arquivísticos ao longo do tempo (CONSELHO NACIONAL DE ARQUIVOS, 2016, p. 29).

3 Objeto digital: objeto digital é definido como todo e qualquer objeto de informação que possa ser representado através de uma sequência de dígitos binários (CONSELHO NACIONAL DE ARQUIVOS, 2016).

4 Relação orgânica é a relação que os documentos que participam de uma mesma ação possuem entre si. Ela pode ser expressa por meio do código de classificação, do Número Único de Protocolo (NUP), do número de matrícula, entre outros (ARQUIVO NACIONAL, 2016).

5 Projeto GEDAI: Comissão de Estudos para Gestão, Preservação e Acesso aos Documentos Arquivísticos Digitais da UFSM criada com a finalidade inicial de elaborar um projeto de informatização da gestão, preservação e acesso aos documentos arquivísticos produzidos pela universidade e, atualmente, desempenha o papel de gerenciar a execução do projeto e orientar as adequações nos sistemas para atender às recomendações e normativas nacionais e internacionais (UNIVERSIDADE FEDERAL DE SANTA MARIA, 2015). 